\title{
Expression of nerve growth factor and its high-affinity receptor Trk-A in the rat pancreas during embryonic and fetal life
}

\author{
F Miralles, P Philippe, P Czernichow and R Scharfmann
}

INSERM U457, Hôpital Robert Debré, 48, Bd. Serurier, 75019 Paris, France

(Requests for offprints should be addressed to F Miralles)

\begin{abstract}
The expression of functional receptors for nerve growth factor in insulin-producing cell lines grown in vitro has recently been demonstrated. The possible importance of signals transduced via these receptors in the control of islet maturation has been proposed based on data obtained using an in vitro culture system. To further support this hypothesis, we have studied the expression of Trk-A, the high-affinity receptor for NGF, in vivo during the embryonic and fetal development of the rat pancreas. We have also examined the expression of NGF during the same period. Immunohistological analysis shows that at embryonic day 11 (E11), Trk-A is expressed by the epithelial cells of the presumptive pancreas. The few pancreatic endocrine cells present at that stage express Trk-A. At E12 and E16, Trk-A expression was detected in
\end{abstract}

the developing ductal network. The endocrine cells located in the ducts express Trk-A while those that have migrated into the surrounding mesenchyme now stain negative for Trk-A. By E20, Trk-A expression by ductal cells has considerably decreased and can be detected only in small ducts closely associated with islet-like structures. These islet-like structures stain negative for Trk-A. After birth, insulin-positive cells arranged into islets re-express Trk-A. During the same period, NGF mRNA is found to be expressed in the developing pancreas. The expression of Trk-A and its ligand NGF in the pancreas during embryonic and fetal life suggests that NGF and its receptor could play an important role in the development of the pancreas.

Journal of Endocrinology (1998) 156, 431-439

\section{Introduction}

Different growth factor receptors such as Trk-A, the high-affinity receptor for nerve growth factor (NGF), first thought to be specifically expressed by neural cells (Barbacid 1994), have recently been described in nonneuronal tissues. Trk-A expression has indeed been detected in different cell types of the hematopoietic tissue (Matsuda et al. 1988, Otten et al. 1989), in the skin (Pincelli et al. 1994) and in endocrine organs including the pancreas (Patterson \& Childs 1994, Kanaka-Gantenbein et al. 1995a, Missale et al. 1995, Dissen et al. 1996).

Our group has recently demonstrated the expression of Trk-A in insulin-producing cell lines ( $\beta$-cell lines) derived from the rat and mouse pancreas (Polak et al. 1993, Scharfmann et al. 1993) and in $\beta$-cells located in the islet of Langerhans of the adult rat pancreas (Kanaka-Gantenbein et al. 1995a). In insulin-producing cells, these NGF receptors are functional: they bind NGF, autophosphorylate and transduce a signal into the cells upon addition of NGF (Scharfmann et al. 1993, Tazi et al. 1995).

Recent evidence for a possible role for the NGF/NGF receptor axis in the development of the islets of Langerhans has emerged. Indeed, it was demonstrated that islets that develop in culture from fetal rat pancreas express Trk-A, while the mesenchymal cells present in these cultures produce NGF (Kanaka-Gantenbein et al. 1995b). More importantly, when the NGF signal-transduction pathway was inhibited, proper development of the islets was impaired (Kanaka-Gantenbein et al. 1995b).

This observation stimulated the research presented in this paper. Our hypothesis was that if NGF plays a role in the development of the endocrine pancreas in vivo, both NGF and its receptor should be expressed at specific stages of pancreatic development. The goal of the present work was thus to study the ontogeny of NGF and Trk-A expression during the different stages of the development of the pancreas. We demonstrate here that NGF and its receptor Trk-A are expressed in the pancreas during early stages of development. These results represent new evidence that NGF and its receptor could be important during early steps of pancreatic development.

\section{Materials and Methods}

Animals and dissection of pancreatic rudiments

Pregnant Wistar rats were purchased from the Janvier Breeding Center (Le Genet, France). The morning of the 
A
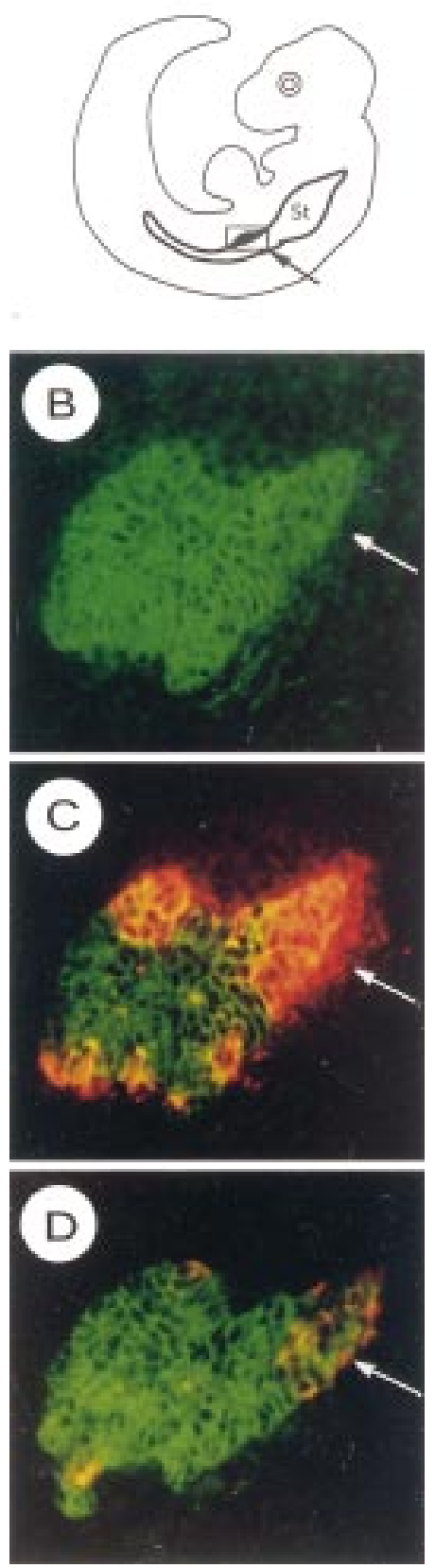

Figure 1 Expression of Trk-A in the early pancreatic primordium. (A) Drawing of a sagittal section of an E11 rat embryo. The boxed area indicates the region of the foregut from which the pancreatic primordium will arise. (B) Trk-A immunostaining on a sagittal section of an E11 rat embryo corresponding to the site boxed in (A). At this stage, all the epithelial cells of the future pancreatic rudiment stain positive for Trk-A (green). (C) The same section stained with both an anti-Trk-A and an anti-glucagon antibody. Glucagon-expressing cells (in red) form clusters (arrows) which are strongly positive for Trk-A (in green). (D) A consecutive section immunostained for both Trk-A (in green) and insulin (in red). This serial analysis reveals that at this stage the majority of the insulin-expressing cells co-express glucagon. Magnification $\times 400$. discovery of the vaginal plug was designated as embryonic day $0.5(\mathrm{E} 0 \cdot 5)$. The pregnant rats were killed by cervical dislocation at different stages of gestation. The whole digestive tract (E11) and the dorsal pancreatic rudiments were obtained by microdissecting the embryos under a Leitz microscope.

\section{Tissue preparation and immunohistology}

The whole gut and the pancreatic rudiments were fixed at $4{ }^{\circ} \mathrm{C}$ in $4 \%$ paraformaldehyde in PBS for $2 \mathrm{~h}$, briefly rinsed with $\mathrm{PBS}$, cryoprotected overnight at $4{ }^{\circ} \mathrm{C}$ in $30 \%$ sucrose and frozen. Consecutive sections $(6 \mu \mathrm{m}$ thick) were cut and collected on gelatinized glass slides. For immunostaining, the sections were first incubated for $30 \mathrm{~min}$ in PBS containing 3\% BSA. Subsequently the sections were incubated for $2 \mathrm{~h}$ at room temperature (or overnight at $4{ }^{\circ} \mathrm{C}$ ) with the primary antibodies. After a wash in PBST (PBS containing 0.5\% Tween 20), the sections were incubated with the appropriate fluorescent secondary antibodies. Finally the sections were extensively washed in PBST and mounted with a fluorescence protecting medium (Vectashield, Vector Laboratories Inc., Burlingame, CA, USA). The sections were examined and photographed with a Leitz DMRD microscope.

The antisera employed in this study were: rabbit polyclonal anti-Trk-A (763; Santa Cruz Biotechnology Inc., Santa Cruz, CA, USA; 1:200 dilution; specific for Trk-A and does not cross-react with other members of the Trk family (Hoehner et al. 1995); has been widely used to detect Trk-A by immunocytochemistry (Patterson \& Childs 1994, Hoehner et al. 1995, Kanaka-Gantenbein et al. 1995a, Dissen et al. 1996)); mouse anti-porcine glucagon (Sigma, St Louis, MO, USA; 1:2000 dilution); rabbit anti-human amylase (Sigma; 1:2000 dilution); mouse anti-porcine vimentin (clone: V9, Dako,

Figure 2 Expression of Trk-A in the pancreatic rudiment at E12.5 and E14. (A) Sagittal section of an E12.5 rat pancreatic rudiment showing both the dorsal (d) and the ventral (v) buds and their surrounding mesenchymal cap $(\mathrm{m})$. Double immunostaining using anti-Trk-A (green) and anti-vimentin (red) antibodies. (B-D) Consecutive sections of an E12.5 dorsal pancreatic rudiment stained with anti-Trk-A (green) (B), anti-Trk-A (green) and anti-glucagon (red) (C) or antiTrk-A (green) and anti-insulin (red) antibodies (D). Arrows indicate clusters of glucagon-positive cells localized in the epithelial bulb and strongly labeled with the anti-Trk-A antibodies. Arrowheads indicate glucagon- or insulin-expressing cells which form clusters budding into the surrounding mesenchyme. These clusters stain very weakly positive for Trk-A. (E) Sagittal section of an E14 dorsal pancreatic rudiment stained for Trk-A (in green) and vimentin (in red). ( $F-H$ ) Consecutive sections of an E14 pancreatic rudiment stained with anti-Trk-A (in green) (F), anti-Trk-A (green) and anti-glucagon (in red) (G) or anti-Trk-A (green) and anti-insulin (red) (H) antibodies. At this stage, the majority of the endocrine cells are localized in the interstitial tissue (arrowheads) and do not stain for Trk-A. Magnifications: A and E $\times 100 ; B, C, D, F, G$ and $H \times 200$. 

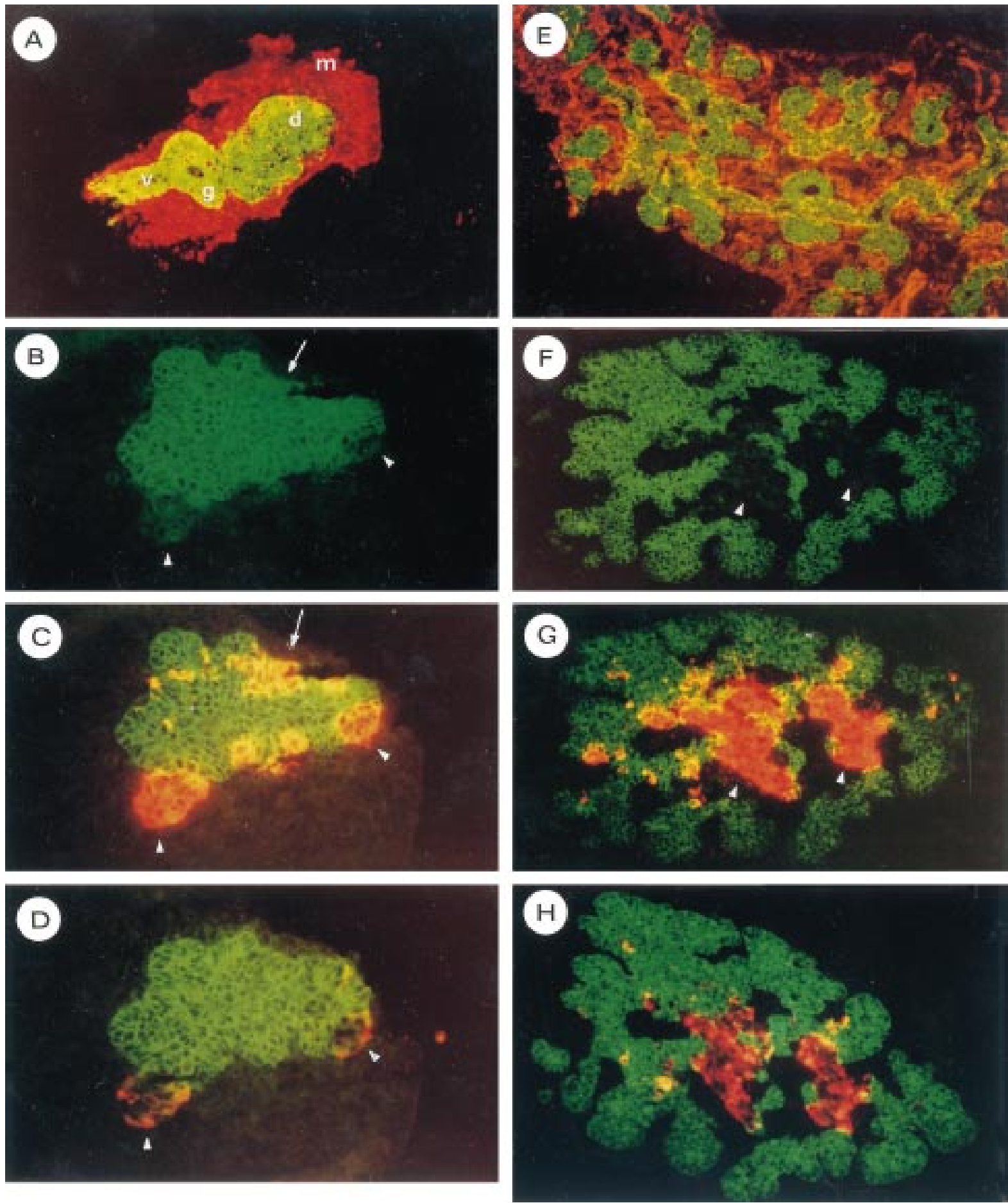
Copenhagen, Denmark; 1:30 dilution); and mouse antihuman insulin (Sigma; 1:2000 dilution). The fluorescent secondary antibodies were from Jackson Immunoresearch (PA, USA): fluorescein anti-mouse antibodies, dilution 1:200; fluorescein anti-rabbit antibodies, dilution 1:500; and Texas-red anti-mouse antibodies, dilution 1:200.

Co-localization of two antigens was determined by double-labeling immunofluorescence. For this purpose, antibodies prepared in two different species were used and revealed using anti-species antibodies labeled with two different fluorochromes. Single labeled sections incubated with mismatched secondary antibodies showed no immunostaining, confirming the specificity of the secondary antisera. Further immunohistological specificity tests included incubation with non-immune primary sera and, in the case of the Trk-A antibody, preincubation of the antibody for $2 \mathrm{~h}$ with a 10 -fold excess of the peptide used to raise the antibody.

\section{Reverse transcriptase (RT)-PCR and Southern blot analysis}

Total RNAs from embryonic, fetal and adult pancreases were extracted using the guanidinium thiocyanatephenol-chloroform procedure (Chomczynski \& Sacchi 1987). For cDNA preparation, $8 \mu \mathrm{g}$ total RNA were first treated with RNase-free DNase and then reverse transcribed. Synthesis of the first strand was performed using random hexamers as previously described (Tazi et al. 1996). The reaction was performed in the presence or absence of RT and allowed to proceed for $1 \mathrm{~h}$ at $37^{\circ} \mathrm{C}$. The following oligonucleotide primers were used for PCR: rat Trk-A (sense), 5'-ATGGCTGCCTTTATGG ACAACC-3'; rat Trk-A (antisense), 5'-GACCCCAAA AGGTGTTTCGTCC-3'; rat NGF (sense), 5'-CTCTG AGCATAATGGGCAGGTAGCT-3'; rat NGF (antisense), 5'-ACTCGGACTGAAATCTGAAG TTCT3'; cyclophilin (sense), 5'-ATGGTCAACCCCACCGT GTT-3'; cyclophilin (antisense), 5'-CGTGTGAAGTCA CCACCCT $-3^{\prime}$.

Thirty cycles of amplification were performed on a water-cooled cycler. Amplification parameters included a 1 min denaturing step at $92^{\circ} \mathrm{C}$, a 1 min annealing step at $55^{\circ} \mathrm{C}$ and a 2 min extension step at $72{ }^{\circ} \mathrm{C}$. The amplified material was then run on a $1.5 \%$ agarose gel analyzed by electrophoresis and transferred to a Hybond-N membrane. Membranes were cross-linked by exposure to UV light. Hybridization was carried out by the method of Church \& Gilbert (1984) using as probe either the 464 bp XGal-SacI fragment from the plasmid pDM 97 corresponding to the extracellular domain of rat Trk A (a gift from L Parada and D Martin-Zanca) or a cDNA corresponding to NGF (Whittemore et al. 1988). Filters were then washed $(3 \times 15 \mathrm{~min})$ in $0.5 \times \mathrm{SSC}$ containing $0 \cdot 1 \%$ SDS. Autoradiography was performed at $-70{ }^{\circ} \mathrm{C}$ with FujiRx film.

\section{Results}

Immunostaining analysis of Trk-A expression during pancreatic development

Sagittal sections of E11 rat whole gut, comprising the stomach, the pancreatic primordium and the primitive intestine (Fig. 1A), were probed with the anti-Trk-A (763) antibody combined with either anti-glucagon or anti-insulin antibodies. At this stage, the region of the pancreatic primordium was found to stain positive for Trk-A, insulin and glucagon. All epithelial cells stain positive for Trk-A, while the mesenchymal cells stain negative (Fig. 1B). Double immunofluorescence staining using anti-Trk-A and anti-glucagon antibodies clearly shows that the majority of the glucagon-expressing cells are labeled by the anti-Trk-A antibody (compare Fig. 1B and $\mathrm{C}$ ). The majority of insulin-expressing cells also stain positive for Trk-A (Fig. 1D). As previously described (Alpert et al. 1988, Jackerott et al. 1996), at that stage, the insulin-expressing cells co-express glucagon (compare Fig. 1C and D).

By E11.5 the pancreatic primordium starts to evaginate into the surrounding mesenchyme to form the dorsal pancreatic rudiment. At E12.5 the pancreatic rudiment appears as a small bulb of epithelium surrounded by a cap of mesenchymal tissue. Double immunohistological analysis using antibodies against vimentin (a mesenchymal marker) and Trk-A shows that the epithelial bulb strongly stains positive with the anti-Trk-A antibody while the surrounding mesenchyme does not react with the antiTrk-A antibody (Fig. 2A and B). At this stage, endocrine cells can be detected by immunostaining either in the epithelial mass or forming small clusters budding into the surrounding mesenchyme (Fig. 2C and D). Insulinpositive cells stain positive for glucagon (compare Fig. 2C and D). Double immunofluorescence study using antiTrk-A and either anti-glucagon or anti-insulin antibodies shows that, while the endocrine cells located within the central epithelial mass stain positive for Trk-A, the endocrine cells budding from it and located in the mesenchyme stain very weakly positive for Trk-A (Fig. $2 \mathrm{~B}, \mathrm{C}$ and $\mathrm{D}$ ).

At E14, a complex ductal network is found. The mesenchymal tissue is located between the branches of the ducts. While the ductal cells are strongly labeled with the anti-Trk-A antibody, the mesenchymal cells stain negative for Trk-A (Fig. 2E and F). Cells expressing glucagon form big clusters which are located in the interstitial tissue (Fig. 2G). The vast majority of these glucagon-expressing cells stained negative for Trk-A (compare panels $F$ and $G$ of Fig. 2). During this period, the vast majority of the insulin-expressing cells stain negative for Trk-A, while very few stain positive for Trk-A (Fig. 2).

From E14 to E16, the pancreatic rudiment continues to grow and develops its ductal network. At E16, ductal cells stain positive for Trk-A (Fig. 3A). The first acinar 
structures become apparent, which do not express Trk-A (data not shown). Large aggregates of endocrine cells, located in the interstitial tissue but in close contact with the ductal network, stain negative for Trk-A. However, some endocrine cells are detected in the ductal network. These cells stain simultaneously for Trk-A and for either insulin or glucagon (Fig 3A and B; Fig. 3C and D). Cells co-expressing both insulin and glucagon were no longer detected in the E16 pancreases and at the following stages of pancreatic development (data not shown).

At E19, the staining of the ductal network for Trk-A has decreased considerably. Insulin-expressing cells have arranged into spherical structures surrounded by glucagonexpressing cells. These 'islet-like' structures are located in the interstitial tissue usually in close contact with small ducts (Fig. 3E and F). While the small ducts stain positive for Trk-A, insulin-positive cells stain negative, and glucagon-positive cells show a faint Trk-A staining.

In the newborn pancreas, as previously described (Kanaka-Gantenbein et al. 1995a), Trk-A immunostaining was detected in the insulin-expressing cells of the islets of Langerhans and in the small ducts associated with the islets (Fig. $3 \mathrm{G}$ and $\mathrm{H}$ ).

\section{RT-PCR analysis of NGF expression during pancreatic development}

Expression of NGF, the ligand of Trk-A, was analyzed at the RNA level. As shown in Fig. 4, RT-PCR analysis indicates that NGF mRNA is found in the embryonic and fetal pancreas. Trk-A mRNA during pancreatic development was analysed in parallel. It was also found in the embryonic and fetal pancreas.

\section{Discussion}

We have studied the pattern of expression of Trk-A, the high-affinity receptor for NGF, during the different stages of the development of the pancreas, starting at E11 when the first endocrine cells develop. We have also studied in parallel the ontogenic profile of expression of NGF, the ligand for Trk-A.

In rodents, the pancreas develops from the epithelial gut, grows into the surrounding mesenchyme, forming a bud and branches into it (Golosow \& Grobstein 1962, Pictet \& Rutter 1972). We have shown that at E11, before the formation of the pancreatic bud, Trk-A is expressed by the epithelial cells of the primitive foregut. At E12.5, when the dorsal and ventral pancreatic buds develop, Trk-A immunostaining is detected in the vast majority of epithelial cells present in these buds. Subsequently, between E12 and E16, Trk-A expression is found in the actively branching pancreatic epithelium. Thereafter the expression of Trk-A in the epithelial ductal network starts to decrease. By day E19, Trk-A expression has decreased considerably and can be detected only in some small ductal structures which appear to be closely associated with the islets of Langerhans. In the postnatal and adult rat pancreas, Trk-A expression appears to be restricted, as previously described, to the islets of Langerhans (Kanaka-Gantenbein et al. 1995a).

In the 1970s, Pictet \& Rutter (1972) subdivided the development of the insulin-positive cells during embryonic life into three phases. During the first phase ('primary transition'), a first wave of insulin-positive cells develop. Using immunochemistry, we found these first insulin-positive cells at E11 within the pancreatic epithelial mass. At this stage, as described previously (Alpert et al. 1988, Jackerott et al. 1996), all insulin-expressing cells stained positive for glucagon. Double immunostaining with anti-Trk-A (763) and either anti-glucagon or antiinsulin antibodies indicates that the vast majority of these early endocrine cells co-express the Trk-A protein. One day later, at E12.5, the number of glucagon- and insulinpositive cells has increased. Some of these endocrine cells remain located in the central epithelial mass and stain positive for Trk-A. On the other hand, the vast majority of the endocrine cells are now found at the interface between the pancreatic epithelial bud and its surrounding mesenchymal cap. These endocrine cells, which are thought to have migrated from the central epithelial sphere into the surrounding mesenchyme, in the vast majority now stain negative for Trk-A. Thus, during the primary transition, the first insulin-positive cells that stain positive for Trk-A will develop into the central epithelial mass and migrate into the surrounding mesenchyme, while losing their ability to stain for Trk-A.

As described previously (Pictet \& Rutter 1972), the primary transition is followed by a second phase, the 'protodifferentiated phase' (E13/E15). During this period, rapid growth and lobulation of the epithelial component of the pancreatic rudiment is found, leading to the formation of the ductal network. During this phase the endocrine activities remain stable. We found that, at this stage, the endocrine cells are located within the interstitial tissue and mostly stain negative for Trk-A.

According to Pictet \& Rutter (1972), from E16, a second wave of insulin-positive cells develop ('secondary transition'). These new $\beta$-cells are known to develop from putative epithelial stem cells located within the ductules (Pictet \& Rutter 1972, Gu et al. 1994). Our data demonstrate that indeed, starting at E16, a large number of dispersed glucagon- or insulin-containing cells are now detected in the ductal tree. While looking at Trk-A expression, it was clear that, at that stage, these dispersed endocrine cells located within the ducts stain positive for Trk-A. These new $\beta$-cells will next leave the ducts and associate to form aggregates of endocrine cells. During this process, they will lose their ability to express Trk-A and, in contrast with insulin-positive cells located within the 

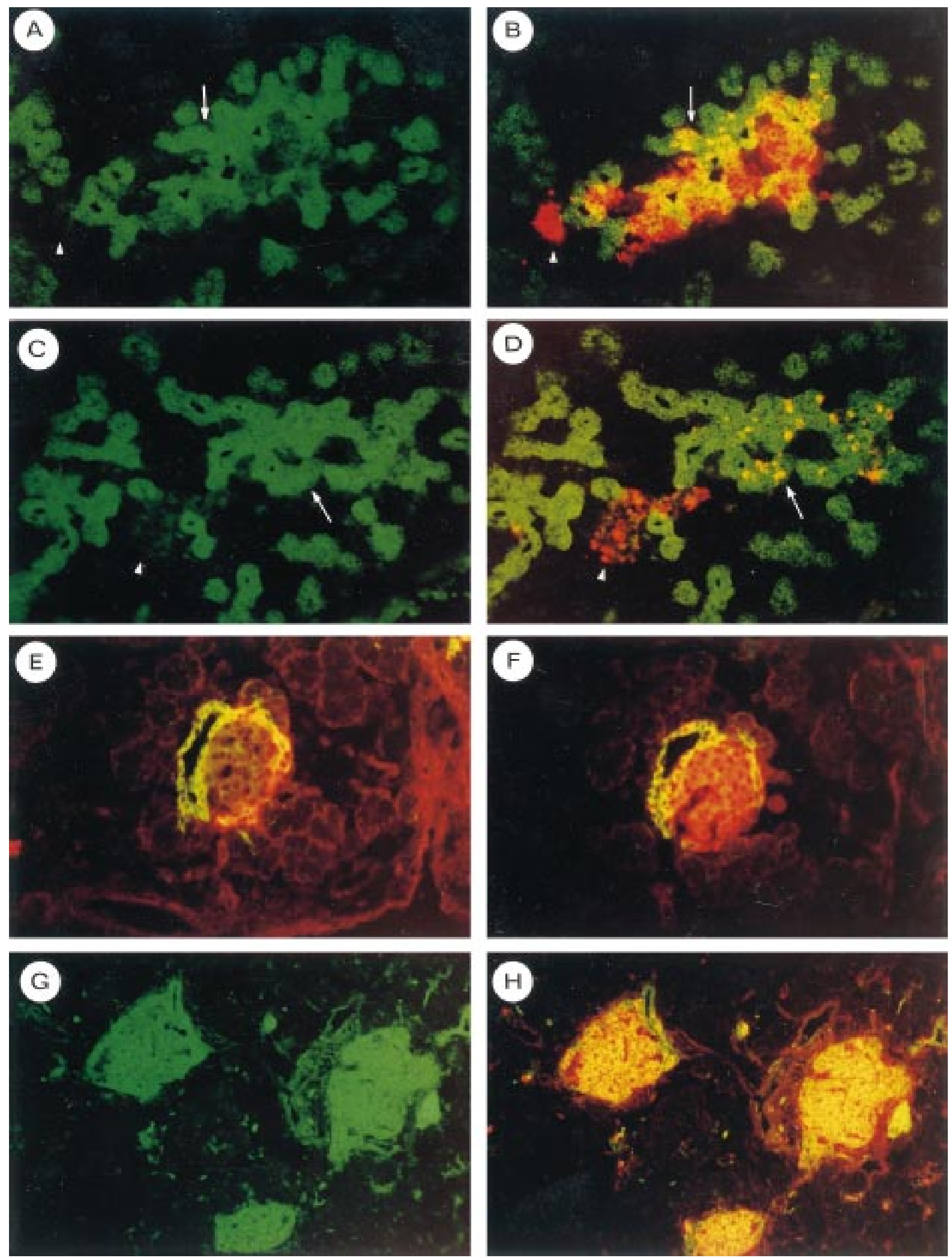
ducts, they will stain negative for Trk-A. Thus, at the beginning of both the primary and secondary transition, when insulin-positive cells are located within the ducts, they express Trk-A. Once they migrate into the surrounding mesenchyme, they lose the ability to express Trk-A. Thus, in vivo, Trk-A expression by insulin-positive cells is tightly controlled and depends on the location of the cells.

In other experimental systems, both in vitro and in vivo, Trk-A expression has been shown to be tightly controlled. For example, in PC12 cells, a cell line derived from a rat pheochromocytoma, NGF up-regulates Trk-A expression (Meakin et al. 1992). In MAH cells, a sympathoadrenal progenitor cell line, depolarizing concentrations of potassium chloride, used to mimic neuronal activity, can induce expression of Trk-A (Birren et al. 1992). Finally, in an insulin-producing cell line, somatolactogenic hormones increase Trk-A expression (Scharfmann et al. 1994), while depolarization decreases Trk-A expression (Atouf et al. 1995). In vivo, Trk-A expression is also tightly regulated. For example, during embryonic and fetal life, in both sensory and sympathetic neurons, Trk-A expression increases with age (Wyatt \& Davies 1993, 1995). Our data suggest that during pancreatic development, Trk-A expression by insulin-expressing cells is also tightly controlled.

The expression of Trk-A by duct cells also follows a specific pattern of expression. While up to E19 all duct cells express Trk-A, after birth Trk-A is found only in a few duct cells, and during adult life, Trk-A expression cannot be detected in duct cells at all. Thus, before birth, when $\beta$-cells develop from stem cells located within the pancreatic ducts (Pictet \& Rutter 1972, Gu et al. 1994), the duct cells express Trk-A. On the other hand, after

Figure 3 Expression of Trk-A and endocrine hormones in pancreases from E16, E19 and newborn rats. (A, B) Immunostaining of an E16 pancreatic section with anti-Trk-A (green) and anti-glucagon (red) antibodies. (A) Single labeling using anti-Trk-A antibody; (B) double labeling with anti-Trk-A and anti-glucagon antibodies. The ductal network is strongly stained with the anti-Trk-A antibodies. Glucagon-expressing cells present in the interstitial tissue (arrowheads) do not stain for Trk-A, while the ones localized in the ductal network (arrows) do stain positive for Trk-A. (C, D) Immunostaining of an E16 pancreatic section with anti-Trk-A (green) and anti-insulin (red) antibodies. (C) Single labeling using anti-Trk-A antibody; (D) double labeling with anti-Trk-A and anti-insulin antibodies. (E) Section of an E19 rat pancreas stained for Trk-A (green) and glucagon (red). At this stage, Trk-A immunostaining is restricted to small ducts which are frequently associated with islet-like structures. Glucagon-expressing cells localize at the periphery of the insular structures and show a very faint staining for Trk-A. The area surrounded by glucagon cells does not stain for Trk-A. The consecutive section in $(F)$ shows that this area contains insulin-expressing cells. $(G, H)$ Double immunostaining for Trk-A (green) and insulin (red) of a newborn rat pancreatic section. Trk-A immunostaining is restricted to the islets and the associated ducts. At this stage all the insulin-expressing cells stain positively for Trk-A. Magnification A, $\mathrm{B}, \mathrm{C}, \mathrm{D}, \mathrm{G}$ and $\mathrm{H} \times 100 ; \mathrm{E}$ and $\mathrm{F} \times 200$. birth, when the budding of new insulin-positive cells from the ductal network does not occur, Trk-A expression is no longer found in the duct cells. It would be interesting to
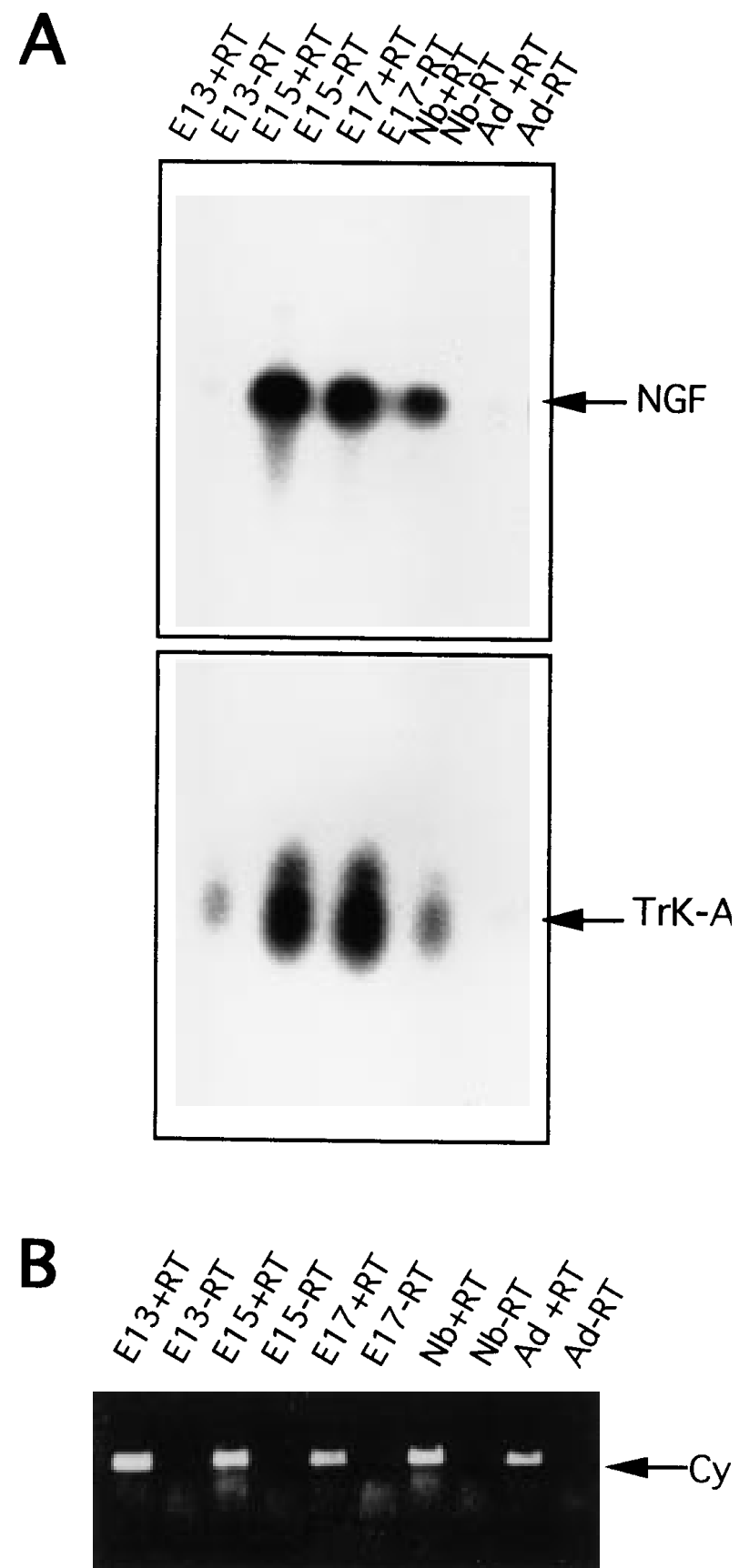

Figure 4 RT-PCR analysis of NGF and Trk-A mRNA expression in the developing pancreas. (A) RNAs were extracted from pancreatic rudiments at the indicated stages, reverse transcribed and assayed for NGF and Trk-A transcripts using the procedures described in Materials and Methods. (B) Amplification of cyclophilin (Cy) was used to assess the quality of cDNA from each sample. $\mathrm{Nb}$, newborn; Ad, adult. 
define whether, in experimental conditions in which new insulin-positive cells develop from adult pancreatic duct cells, such as streptozotocin treatment (Fernandes et al. 1997) or partial pancreatectomy (Bonner-Weir et al. 1993), re-expression of Trk-A can be found within duct cells.

The function of Trk-A in vivo in the pancreas is not yet known. Because, as described here, it follows a specific pattern of expression during pancreatic development, it could play an important role during this period. We have previously demonstrated that, in an in vitro model of islet development, mesenchymal cells surrounding the islets produce NGF, while the endocrine cells express Trk-A. Blocking Trk-A phosphorylation in that system retarded islet cell development (Kanaka-Gantenbein et al. 1995b). It was thus of interest to study whether NGF was expressed in the pancreas during development. By RT-PCR analysis, we show that NGF mRNA is expressed during pancreatic development. The cell type expressing NGF in the pancreas is not known but our data obtained in vitro demonstrating the expression of Trk-A by mesenchymal cells (Kanaka-Gantenbein et al. 1995b) suggest that this could also be the case in vivo. However, in situ hybridization should be performed to define such a cell type. In conclusion, NGF is expressed in the embryonic pancreas. Trk-A, its high-affinity receptor, is expressed by insulinproducing cells at specific stages of their differentiation, at the beginning of the first and secondary transition. In vivo, NGF could thus play a role during the development of the pancreas.

\section{Acknowledgements}

This work was supported by the Juvenile Diabetes Foundation International, the Association pour la Recherche contre le Cancer and the EEC. We would like to thank Olivier Dubois for technical assistance.

\section{References}

Alpert S, Hanahan D \& Teitelman G 1988 Hybrid insulin genes reveal a developmental lineage for pancreatic endocrine cells and imply a relationship with neurons. Cell 53 295-308.

Atouf F, Tazi A, Polak M, Czernichow P \& Scharfmann R 1995 Dexamethasone regulates the expression of neuronal properties of a rat insulinoma cell line. Journal of Neuroendocrinology 7 957-964.

Barbacid M 1994 The Trk family of neurotrophin receptors. Journal of Neurobiology 25 386-403.

Birren S, Verdi J \& Anderson D 1992 Membrane depolarization induces p140trk and NGF responsiveness, but not p75LNGFR, in MAH cells. Science 257 395-397.

Bonner-Weir S, Baxter L, Schuppin G \& Smith F 1993 A second pathway for regeneration of adult exocrine and endocrine pancreas: a possible recapitulation of embryonic development. Diabetes $\mathbf{4 2}$ 1715-1720.

Chomczynski P \& Sacchi N 1987 Single-step method of RNA isolation by acid guanidinium thiocyanate-phenol-chloroform extraction. Analytical Biochemistry 162 156-159.
Church G \& Gilbert W 1984 Genomic sequencing. Proceedings of the National Academy of Sciences of the USA 81 1991-1995.

Dissen G, Hill D, Costa M, Dees WL, Lara H \& Ojeda S 1996 A role for TrkA nerve growth factor receptors in mammalian ovulation. Endocrinology 137 198-209.

Fernandes A, LC LK, Guz Y, Stein R, Wright C \& Teitelman G 1997 Differentiation of new insulin-producing cells is induced by injury in adult pancreatic islets. Endocrinology 138 1750-1762.

Golosow N \& Grobstein C 1962 Epitheliomesenchymal interaction in pancreatic morphogenesis. Developmental Biology 4 242-255.

Gu D, Lee M-S, Krahl T \& Sarvetnick N 1994 Transitional cells in the regenerating pancreas. Development 120 1873-1881.

Hoehner J, Olsen L, Sandstedt B, Kaplan D \& Pahlman D 1995 Association of neurotrophin receptor expression and differentiation in human neuroblastoma. American Journal of Pathology 147 102-113.

Jackerott M, Oster A \& Larsson L 1996 PYY in developing murine islet cells: comparisons to development of islet hormones, NPY, and BrdU incorporation. Journal of Histochemistry and Cytochemistry 44 809-817.

Kanaka-Gantenbein C, Tazi A, Czernichow P \& Scharfmann R 1995 a In vivo presence of the high-affinity NGF receptor TRK-A in the rat pancreas: differential localization during pancreatic development. Endocrinology 136 761-769.

Kanaka-Gantenbein C, Dicou E, Czernichow P \& Scharfmann R $1995 b$ Presence of nerve growth factor and its receptor in an in vitro model of islet cell development: implication in normal islet morphogenesis. Endocrinology 136 3154-3162.

Matsuda H, Coughlin M, Bienenstock J \& Denburg J 1988 Nerve growth factor promotes human hematopoietic colony growth and differentiation. Proceedings of the National Academy of Sciences of the USA 85 6508-6512.

Meakin S, Suter U, Drinkwater C, Welcher A \& Shooter E 1992 The rat trk protooncogene product exhibits properties characteristic of the slow nerve growth factor receptor. Proceedings of the National Academy of Sciences of the USA 89 2374-2378.

Missale C, Boroni F, Frassine M, Curaso A \& Spano P 1995 Nerve growth factor promotes the differentiation of pituitary mammotroph cells in vitro. Endocrinology 136 1205-1213.

Otten U, Ehrhard P \& Peck R 1989 Nerve growth factor induces growth and differentiation of human lymphocytes. Proceedings of the National Academy of Sciences of the USA 86 10059-10063.

Patterson J \& Childs G 1994 Nerve growth factor and its receptor in the anterior pituitary. Endocrinology 135 1689-1696.

Pictet R \& Rutter W 1972 Development of the embryonic pancreas. In Handbook of Physiology, pp 25-66. DF Steiner \& M Frenkel. Washington DC, USA: American Physiological Society.

Pincelli C, Sevegnani C, Manfredini R, Grande R, Fantini F, Lauderio LB, Aloe L, Ferrari S, Cossarizza A \& Gianetti A 1994 Expression and function of nerve growth factor and nerve growth factor receptor on cultured keratinocytes. Journal of Investigative Dermatology 103 13-18.

Polak M, Scharfmann R, Seilheimer BEG, Dressler D, Verma IM \& Potter H 1993 Nerve growth factor induces neuron-like differentiation of an insulin secreting pancreatic beta cell line. Proceedings of the National Academy of Sciences of the USA 90 $5781-5785$.

Scharfmann R, Tazi A, Polak M, Kanaka C \& Czernichow P 1993 Expression of functional nerve growth factor receptors in pancreatic beta cell lines and fetal rat islets in primary culture. Diabetes $\mathbf{4 2}$ 1829-1836.

Scharfmann R, Atouf F, Tazi A \& Czernichow P 1994 Growth hormone and prolactin regulate the expression of nerve growth factor receptors in INS-1 cells. Endocrinology 134 2321-2328.

Tazi A, Czernichow P \& Scharfmann R 1995 Similarities and discrepancies in the signaling pathway for nerve growth factor in an insulin producing cell line and a neural crest-derived cell line. Journal of Neuroendocrinology 7 29-36. 
Tazi A, Bras SL, Lamghitni HO, Vincent J, Czernichow P \& Scharfmann R 1996 Neurotrophin-3 increases intracellular calcium in a rat insulin-secreting cell line through its action on a functional TrkC receptor. Journal of Biological Chemistry 271 10154-10160.

Whittemore S, Friedman P, Larhammar D, Persson H, GonzalezCarvajal M \& Holets V 1988 Rat $\beta$-nerve growth factor sequence and site of synthesis in the rat hippocampus. Journal of Neuroscience Research 20 403-410.
Wyatt S \& Davies A 1993 Regulation of expression of mRNAs encoding the nerve growth factor receptors $\mathrm{p} 75$ and trkA in the developing sensory neurons. Development 119 635-647.

Wyatt S \& Davies A 1995 Regulation of nerve growth factor receptor gene expression in sympathetic neurons during development. Journal of Cellular Biology 130 1435-1446.

Received 16 June 1997

Accepted 18 September 1997 